\title{
DESAFIOS DA ECOLOGIA URBANA
}

Um dos grandes desafios para os próximos anos em relação à qualidade ambiental e consequente qualidade de vida é equacionar o fato de que mais de $80 \%$ da população brasileira se concentra nas cidades. Os problemas dessa concentração populacional estão relacionados com as modificações da estrutura e do funcionamento desse sistema urbanizado. Ou seja, em primeiro plano, as mesmas questões de sempre: água, lixo, transporte, arborização, qualidade do ar. Mais especificamente, fornecimento de água limpa em quantidade suficiente; a construção de redes de esgoto; o tratamento de efluentes domésticos e industriais; drenagem; produção e acumulo de lixo; o automóvel como principal meio de transporte; poluição atmosférica; ausência de áreas verdes, distribuição de renda.

Esse desafio deve ser tratado a partir de uma abordagem sistêmica e, como já descrito na literatura, é preciso considerar as inter-relações entre a comunidade e suas múltiplas interações com o ambiente. Significa investigar os padrões ecossistêmicos, modelos de desenvolvimento humano e a percepção pela comunidade dessas questões. Essas informações, por sua vez, servirão para subsidiar políticas públicas e desejavelmente gerar ações exitosas na solução desses problemas. Essa perspectiva multidimensional do espaça urbano depende do trabalho de grupos multidisciplinares e de disponibilidade de dados e informações. Entramos, então, em duas questões fundamentais: maturidade do profissional que deve lidar com essas novas formas de entendimento dos problemas socioeconômicos e ambientais, e a qualidade e visibilidade dos trabalhos acadêmicos. O primeiro ponto provavelmente seja um caminho particular, uma busca pessoal. Já o segundo depende da disponibilização irrestrita dos documentos acadêmicos em seus diferentes formatos. As revistas têm papel fundamental e a Revista UNIARA vem, nos últimos anos, investindo na sua estrutura, conteúdo, periodicidade e no processo de indexação, com destaque para maior visibilidade e facilidade de acesso - para isso, tem-se trabalhado na elaboração e disponibilização da sua versão digital.

Uma abordagem integrada como a Ecologia Urbana pode desgastar-se em razão dos problemas de comunicação entre pesquisadores e outros atores sociais, pela ausência de intercâmbio de teorias e métodos; mas não deve consumir-se em função da indisponibilidade irrestrita de dados e informações acadêmicos.

\section{Os Editores}

